\title{
Low weight additive manufacturing FBG accelerometer: design, characterization and testing
}

\author{
N. Gutiérrez ${ }^{\mathrm{a}}$, P. Galvín ${ }^{\mathrm{b} *}$, F. Lasagni ${ }^{\mathrm{a}}$ \\ a Advanced Center for Aerospace Technologies (CATEC), \\ C Wilbur y Orville Wright 19, 41309 La Rinconada (Sevilla), Spain \\ E-mail: ngutierrez@catec.aero, flasagni@catec.aero \\ ${ }^{\mathrm{b}}$ Escuela Técnica Superior de Ingeniería, Universidad de Sevilla \\ Camino de los Descubrimientos s/n, 41092 Sevilla, Spain \\ E-mail: pedrogalvin@us.es
}

* Corresponding author: Pedro Galvín

Preprint submitted to Measurement

\begin{abstract}
Structural Health Monitoring is considered the process of damage detection and structural characterization by any type of on-board sensors. Fibre Bragg Gratings (FBG) are increasing their popularity due to their many advantages like easy multiplexing, negligible weight and size, high sensitivity, inert to electromagnetic fields, etc. FBGs allow obtaining directly strain and temperature, and other magnitudes can be also measured by the adaptation of the Bragg condition. In particular, the acceleration is of special importance for dynamic analysis. In this work, a low weight accelerometer has been developed using a FBG. It consists in a hexagonal lattice hollow cylinder designed with a resonance frequency above $500 \mathrm{~Hz}$. A Finite Element Model (FEM) was used to analyse dynamic behaviour of the sensor. Then, it was modelled in a CAD software and exported to additive manufacturing machines. Finally, a characterization test campaign was carried out obtaining a sensitivity of $19.65 \mathrm{pm} / \mathrm{g}$. As a case study, this paper presents the experimental modal analysis of the wing of an Unmanned Aerial Vehicle. The measurements from piezoelectric, MEMS accelerometers, embedded FBGs sensors and the developed FBG accelerometer are compared.
\end{abstract}

Key words: structural health monitoring (SHM); Fibre Bragg Grating (FBG); accelerometer; additive manufacturing 


\section{INTRODUCTION}

Structural Health Monitoring (SHM) consists of structural integrity evaluation by means of data acquisition and analysis directly from on-board sensors [1]. SHM has many advantages as follows. SHM methodologies can detect changes in material or geometric conditions, which can cause negative or dangerous effects on the system performance. Furthermore, on-line real-time information is relevant for increasing safety, optimizing maintenance operations and reducing costs. Additionally, a continuously monitored structure allows the designers to update design parameters and reduce structural weight without penalizing safety [2,3].

During the last two decades, structural monitoring techniques and sensors have undergone an exponential growth. Several researches about sensors like strain gauges, piezoelectric patches/accelerometers, fibre optic distributed sensing and Fibre Bragg Gratings have been presented. FBG is a promising alternative to conventional sensors due to its many advantages. FBG sensors use light instead of electricity allowing their introduction into dangerous environments. They are not affected by electromagnetic fields and can be easily multiplexed. Their negligible size and weight allow them to be embedded without modifying the material mechanical characteristics. FBGs are sensitive to strain and temperature, which can be measured at high frequency rates [4-6]. They have been already widely used as a viable replacement of strain gauges in both laboratory [7-9] and real use applications, in aeronautics [10,11], civil [12] and nautical [13] engineering fields showing a high technology readiness level [14]. Fibre Optics (FO) is also used as a temperature sensor [15-17], for strain/temperature compensation [18-20] and for curing monitoring of Fibre Reinforced Plastics [21,22].

FBG can also be used for measuring other magnitudes adapting the Bragg condition $[23,24]$. Although monitoring of strain is essential for the structural integrity analysis in static or low time-dependent cases, when dynamic events occur it is also needed recording the acceleration magnitude. FO can be adapted to measure accelerations by using mainly two types of mechanism: (i) axial/cylindrical and (ii) perpendicular or cantilever.

Axial or cylindrical accelerometers work with a mass supported by a linear spring where the FO is installed. The inertial mass displacement occurs in the same axis of the FBG sensor. Several authors have developed accelerometers using this principle. The sensitivity is given in $[\mathrm{V} / \mathrm{g}]$ or $[\mathrm{m} / \mathrm{g}]$ depending on the equipment used for measuring the 
signal from the fibre, being $g$ the acceleration of gravity. The first one is normally reported when a superluminiscent light emitting diode or laser and a photodiode are used. In this case, the voltage is an output of the system. Alternatively, in the second case, wavelength differences are obtained from interrogators systems. Next, some proposals are briefly discussed.

Morikawa et al. [25] developed a triaxial accelerometer in which FOs are used as spring elements with a central oscillating mass of 1 gram, but the needed stiffness of the shell elevates the total weight of the sensor up to approximately 50 grams. The authors measured a resonance frequency of $800 \mathrm{~Hz}$. Fender et al. [26] also used the FO as a spring for a monoaxial sensor. The mass was added as an epoxy drop of between 0.55 and 4.82 milligrams. The aluminium housing of the sensor increased the total weight of the accelerometer to 15 grams. Zhang et al. [27] embedded the FBG in a silicone cylinder. They used an inertial mass of 9 grams obtaining a resonance frequency of $400 \mathrm{~Hz}$ and a sensitivity of $42.7 \mathrm{pm} / \mathrm{g}$. Guozhen et al. [28] proposed another accelerometer where the fibre was embedded in a cylinder. In this case, it was made of aluminium and they used it as spring and inertial mass at the same time. The total weight of the sensor was 25 grams and the authors reported a flat frequency response function from 800 to $5000 \mathrm{~Hz}$. Costa Antunes et al. [29] developed a biaxial accelerometer with sensitivities of 87.85 and $92.35 \mathrm{pm} / \mathrm{g}$ and resonant frequencies of 846.01 and $845.33 \mathrm{~Hz}$. The FO was installed across the inertial mass by some slots in the surface. The aluminium inertial mass of approximately 254 grams was a $50 \mathrm{~mm}$ diameter cylinder that moves perpendicular to the clamping. Liu et al. [30] designed an axial accelerometer using a double steel diaphragm as spring. One of the FO ends was glued to the inertial mass and the other one to the shell of the sensor. The effective mass was 9 grams but the total mass was not specified. They obtained a resonant frequency of $1240 \mathrm{~Hz}$ and a sensitivity in the range from 0 to $400 \mathrm{~Hz}$ of $23.8 \mathrm{pm} / \mathrm{g}$. Jiang et al. [31] developed a triaxial accelerometer based on a 10 grams suspended mass hanged by 3 optical fibres. They registered a resonance frequency of $160 \mathrm{~Hz}$. Dai et al. [32] presented a sensor consisting in two symmetrical flexible beams as elastic elements and inertial masses. They measured a resonant frequency of approximately $2900 \mathrm{~Hz}$ and a sensitivity from $14.64 \mathrm{pm} / \mathrm{g}$ at $100 \mathrm{~Hz}$ to $16.43 \mathrm{pm} / \mathrm{g}$ at $1000 \mathrm{~Hz}$. Wang et al. [33] designed, analysed and optimised an axial accelerometer based on an elastic pipe, consisting of two flexible cylinders in a push-pull configuration with the inertial mass in the middle. The authors reported a sensitivity of $623 \mathrm{pm} / \mathrm{g}$ with a mass 
of 56 grams and a resonant frequency of $449 \mathrm{~Hz}$. Sun et al. [34] developed a sensor based on a cantilever beam with the FBG installed in the perpendicular direction. They obtained a sensitivity from 2028 to $2548 \mathrm{pm} / \mathrm{g}$ with a resonant frequency of approximately $37 \mathrm{~Hz}$ using an inertial mass of 568 grams.

Another mechanism found in literature for manufacturing accelerometers is placing the FBG perpendicular to the inertial mass displacement, normally in form of cantilever structures. Some authors have researched about this topic [35-42]. Thériault et al. [35] and López-Higuera et al. [36] used the fibre as both sensor and cantilever beam. L-shaped clamped structures were employed by Antunes et al. [37,38] and Wang et al. [39]. Also, accelerometers based on clamped beams have been developed using regular section [42], non-uniform section [40] and by a double beam to reduce the transversal sensitivity [41]. The authors adjusted the sensors properties depending on the structure to be analysed: inertial mass from 15.8 to more than 50 grams; sensitivity from $75 \mu \mathrm{V} / \mathrm{g}$ and $20 \mathrm{pm} / \mathrm{g}$ to $6860 \mathrm{mV} / \mathrm{g}$ and $306 \mathrm{pm} / \mathrm{g}$; and resonant frequency between 40 and $2950 \mathrm{~Hz}$.

Additive manufacturing (AM), also called rapid manufacturing [43] or rapid prototyping [44], is defined by the American Society for Testing and Materials as the "process of joining materials to make objects from 3D model data, usually layer upon layer" [45]. This technology has been many times referred in the latest publications as "the third industrial revolution" due to its capacity to change the manner engineering parts and structures can be fabricated $[46,47]$. AM allows the manufacturing without geometrical constraints by CAD design, avoiding unnecessary waste of material and cutting tools. Auxiliary parts like springs or mechanisms can be integrated in the main component. Moreover, fibre routing, holes for connectors and ad-hoc casings can be easily made. The combination of FBG and AM allows the development of optimized structures with integrated sensors and light weight. Nowadays, many AM technologies are available: fused deposition modelling [48], inkjet printing, laminated object manufacturing, stereolithography, selective laser sintering $[49,50]$, etc.

This paper presents a work of complementation between two very promising technologies: FBG and AM. The objective is the development of an accelerometer of low weight based on a FBG, focused on structural health monitoring of aeronautical structures. The paper is organized as follows. Firstly, some analytical formulation, design and manufacturing steps are discussed. Next, a finite element model is developed to estimate the behaviour of the accelerometer. Then, a test campaign is carried out for 
characterization. Finally, the sensor is used in the modal analysis of a wing of an Unmanned Aerial Vehicle (UAV) for validation purposes.

\section{THEORY, DESIGN AND MANUFACTURING}

An FBG is a sensor photo-inscribed by an ultraviolet laser in the core of fibre optics. It is a passive optical device based on a pattern of permanent different refractive index, so called grating or fixed index modulation. This results in an optical filter or mirror for determined wavelength depending on the Bragg condition (Eq. 1) [51]:

$$
\lambda_{B}=2 n_{e f f} \Lambda
$$

where $\lambda_{B}$ is the Bragg wavelength, $n_{\text {eff }}$ is the index of refraction and $\Lambda$ is the grating period. FBGs are sensitive to strain and temperature. Eq. 2 can be obtained from Eq.1 by derivation:

$$
\Delta \lambda_{B}=2\left(\Delta \frac{\partial n_{e f f}}{\partial L}+n_{e f f} \frac{\partial \Lambda}{\partial L}\right) \Delta L+2\left(\Lambda \frac{\partial n_{e f f}}{\partial T}+n_{\text {eff }} \frac{\partial \Lambda}{\partial T}\right) \Delta T
$$

where the first term stands for effects related to strain and the second one to temperature. In the temperature term, the left factor is related to the thermo optic coefficient of the fibre $\left(\alpha_{n}\right)$ and the right one to the thermal expansion coefficient $\left(\alpha_{\Lambda}\right)$. In this work, the tests are developed in a controlled atmosphere and the temperature effects can be neglected. Therefore, this term will not be further considered. The strain term in Eq. 2 can be decomposed as:

$$
\Delta \lambda_{B}=\lambda_{B}\left[1-\frac{n_{\text {eff }}^{2}}{2}\left(p_{12}-v\left(p_{11}-p_{12}\right)\right)\right] \varepsilon
$$

where $p_{11}$ and $p_{12}$ are the components of the strain-optic tensor, $v$ is the Poisson's ratio of the fibre and $\varepsilon$ is the strain in the longitudinal axis. Several research works previously presented $[3,7,8,52]$ assure that these coefficients are linear in the range from -5000 to $5000 \mu \varepsilon$, or even up to $10000 \mu \varepsilon$, depending on the model of the fibre optic. Therefore, they can be replaced by a coefficient P:

$$
\Delta \lambda_{B}=\lambda_{B}[1-P] \varepsilon
$$

this value can be found in literature from 0.15 to $0.22[3,27,30]$ depending on the fibre and set-up. 
Any sensor based on FBG needs a transformation from the required magnitude (acceleration, quantity of oxidation, displacement, etc.) to strain or temperature in the range of linearity of the grating. The sensor proposed in this work is based on a compliant cylinder with a mass on the top, which can be modelled as a one degree of freedom (DOF) mass-spring system (Figure 1).

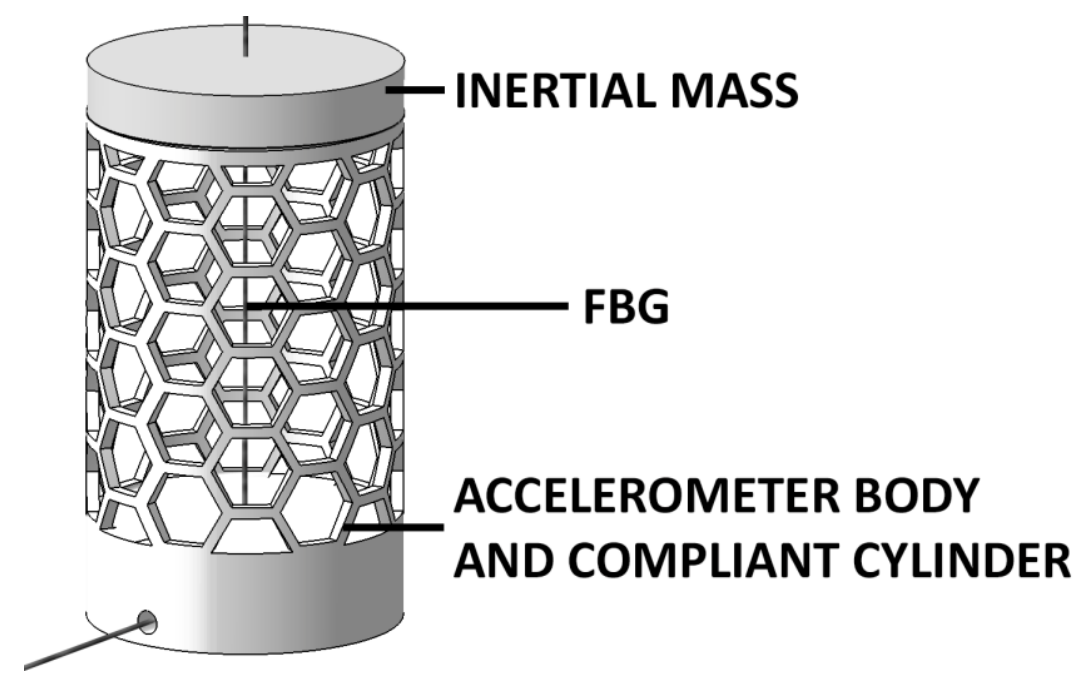

Figure 1. CAD view of the proposed accelerometer: inertial mass, FBG and accelerometer body.

In the design of an accelerometer, two parameters are the most characteristics of its performance: natural frequency and sensitivity. Nevertheless, the damping ratio should be also accounted for. According to the mechanics of a simple 1-DOF harmonic oscillator (with no damping), the natural frequency $\left(f_{n}\right)$ of the system can be expressed as in Eq. 5:

$$
f_{n}=\frac{1}{2 \pi}\left(\frac{k_{\text {eff }}}{m_{\text {eff }}}\right)
$$

where $k_{\text {eff }}$ and $m_{\text {eff }}$ are the effective stiffness and mass. In the proposed sensor, the body and the FBG contributed to the stiffness. The mass contribution was mainly due to the one placed on the top.

The acceleration level can be expressed by the Newton's second law and the Hook's law as in Eq. 6. The sensitivity of the sensor $(S)$ is defined as the ratio between the wavelength increment recorded by the FBG and the acceleration (a) (Eq. 7). Then, introducing the 
acceleration from Eq. 6 into Eq. 7, the sensitivity can be expressed as a function of accelerometer characteristics (Eq. 8):

$$
\begin{gathered}
F=m_{\text {eff }} a \rightarrow a=\frac{F}{m_{\text {eff }}} \rightarrow a=\frac{k_{\text {eff }} \Delta L}{m_{\text {eff }}} \\
S=\frac{\Delta \lambda_{B}}{a} \\
S=\lambda_{B}(1-P) \varepsilon / \frac{k_{\text {eff }} \Delta L}{m_{\text {eff }}}
\end{gathered}
$$

being $\Delta L$ the increment of length of the body of the sensor.

In this work, a Micron Optics OS1100 commercial FBG sensor was used. This was coated in polyimide with an external maximum diameter of $165 \mu \mathrm{m}$. The core and cladding diameters were 9 and $125 \mu \mathrm{m}$, respectively, and it had a length of $10 \mathrm{~mm}$. The Bragg wavelength of the sensor was $1520 \mathrm{~nm}$ with a sensitivity (to measure strains) equal to $1.2 \mathrm{pm} / \mu \varepsilon$. The equipment used to read the sensors was a Micron Optics SM130-700. This device can acquire data from 80 sensors per channel from $1510 \mathrm{~nm}$ to $1590 \mathrm{~nm}$ at a maximum sampling frequency of $1000 \mathrm{~Hz}$ in four channels simultaneously, with $2 \mathrm{pm}$ of typical wavelength stability and $1 \mathrm{pm}$ of repeatability.

The designed FBG accelerometer should have a resonance frequency that allows its application to aerospace structures. Derkevorkian et al. [53] measured natural frequencies of 2.4, 14.677, 41.096 and $80.530 \mathrm{~Hz}$ in an aluminium wing and Bertucci et al. [54] studied a maximum frequency of $100 \mathrm{~Hz}$ for the dynamic characterization of helicopters primary flight control systems. Therefore, the objective of the present work was the design of an accelerometer to study a maximum frequency about $200 \mathrm{~Hz}$. The device should be lightly damping and rigid enough to withstand its practical use, reduce its transverse sensitivity and to allow the connection of the fibre in both edges to be multiplexed in the same FO line with other sensors. Moreover, the length of the cylinder needed to be enough to install the $10 \mathrm{~mm}$ sensor. On the other hand, in order to reduce the transverse sensitivity, the cylinder should not be slender. From a numerical analysis and manufacturing requirements, a cylinder $25 \mathrm{~mm}$ length and $20 \mathrm{~mm}$ diameter was built. The sensor was modelled in CATIA V5 software and then exported to a manufacturing machine. Selective Laser Sintering (SLS) was used as manufacture method, due to its 
freedom to quickly build complex parts, fast build time, better part functionality and no post curing needed. SLS used a laser to draw each layer over the manufacturing surface. It consisted on a powder bed of material preheated just some degrees below its melting point. The sintered material formed the part, whiles the un-sintered remained and needed to be removed after the manufacturing process. The shell of the accelerometer was manufactured in a 3D Systems Sinterstation HiQ SLS machine using polyamide. It consisted in a hexagonal lattice cylinder for reducing its mass. FO was routed inside, prestressed and glued in both extremes. The metal inertial mass was manufactured in a Renishaw MTS AM250 machine in Ti64 and fixed on top of the sensor. The total weight (including the shell, fibre and inert mass) of the sensor was 9.19 grams. Therefore, due to its low weight and size, it is feasible the deployment at high number of locations on the structure to estimate the change in the modal properties or the detection of sudden loads or impacts with high spatial accuracy.

In relation to the damping ratio, Faustini et al. [55] studied the polyamide material and they found a damping ratio of 0.014. Taillon et al. [56] obtained damping ratios lower than 0.05 in metallic lattice structures. Mita et al. [57,58] developed two accelerometers with damping ratios of 0.025 and 0.028 based on metallic L-shape cantilever beams with the fibre as sensor and flexible element. According the previously indicated data and the characteristics of the proposed accelerometer (polyamide lattice structure), a light damping ratio about 0.02 was expected.

\section{NUMERICAL SIMULATIONS}

NASTRAN software was used as FEM processor to develop the numerical model of the accelerometer. The shell of the sensor defined by its surfaces was imported in igs format into PATRAN software. The mesh consisted of 55550 cquad elements (Figure 2). The fibre was modelled as a cbar clamped to the base and stiffly joined to the top. As boundary conditions, the base was fixed. The mass was simulated as a non-structural mass at the central point of the upper cylinder joined to the shell by a rigid element (RBE2). The material properties introduced in the software were the following. Polyamide DURAFORM® PA: Young Modulus $1.59 \mathrm{GPa}$, Poisson's ratio 0.35 and a density $1 \mathrm{~g} / \mathrm{cm}^{3}$ [59]; FO: Young Modulus $65 \mathrm{GPa}$ [60] and Poisson's ratio 0.3. The inertial mass was 6.59 grams. 


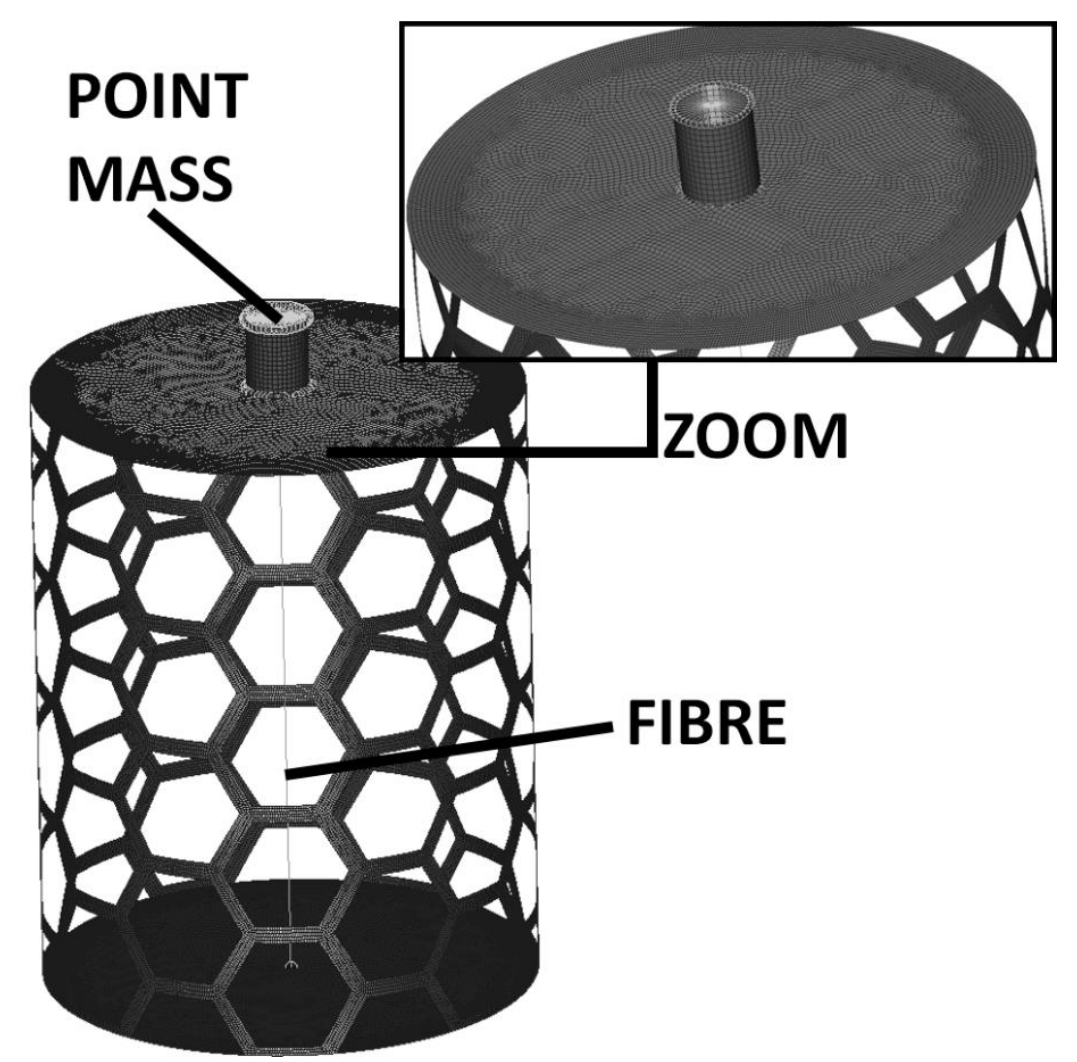

Figure 2. Mesh of the accelerometer numerical model.

Next, the dynamic problem was solved to obtain the mode shape and the natural frequencies of the first three modes of vibration of the modelled sensor. The natural frequencies obtained from the analysis were 137, 138 and $708 \mathrm{~Hz}$. Figure 3 shows the computed mode shapes. The first and the second frequencies correspond to bending mode shapes in perpendicular directions and the third one to an axial mode. 
$1^{\text {st }}$ AND $2^{\text {nd }}$

EIGENMODES

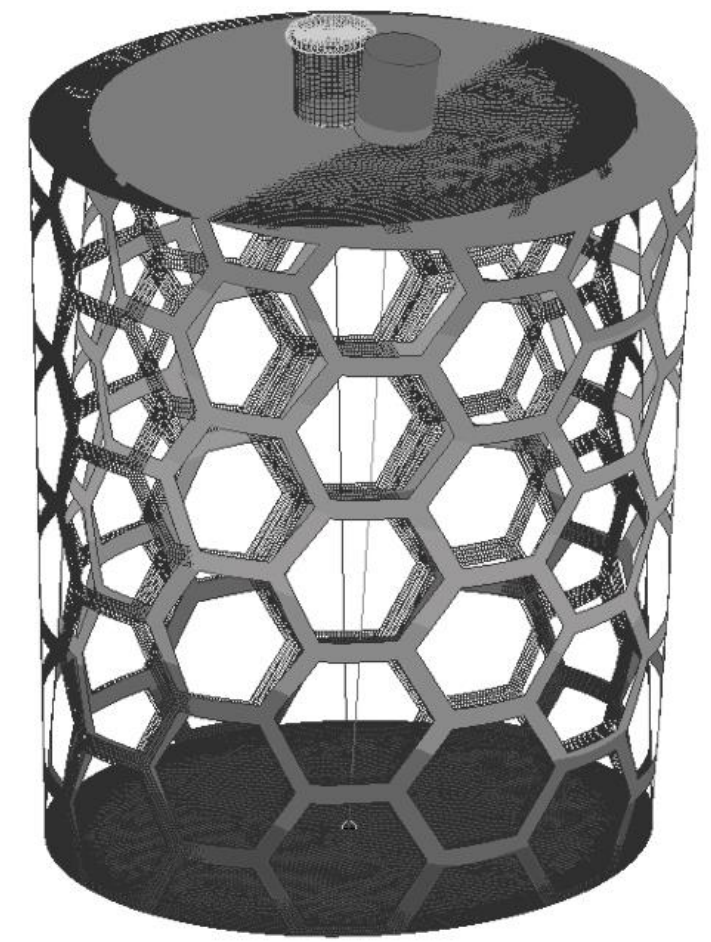

$3^{\text {rd }}$

\section{EIGENMODE}

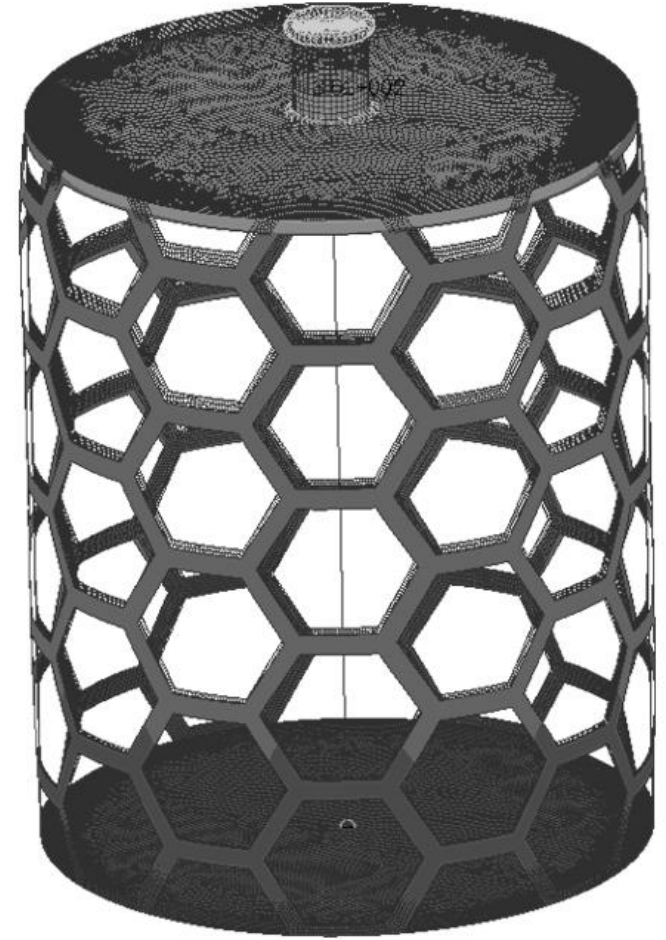

Figure 3. Numerical mode shapes (the first and the second mode shapes were bending modes in perpendicular directions).

The model was then subjected to a series of dynamic loads in order to compare numerical results with experimental data. An acceleration of $1 \mathrm{~g}$ of amplitude with harmonic time dependence was applied as boundary condition in the base of the sensor in the range from 10 to $800 \mathrm{~Hz}$ with a frequency step of $10 \mathrm{~Hz}$. The sensitivity of the accelerometer was computed from the fibre strain by the Eq. 4 with a value of $P$ equal to 0.19 [61]. The computed results will be presented in the next Section (Figure 6).

\section{CHARACTERIZATION TESTS AND RESULTS}

The set-up scheme is shown in Figure 4. The accelerometer was placed in a support manufactured by fused deposition modelling in acrylonitrile butadiene styrene plastic. Fibre optic was fixed to the wall of the test chamber approximately one meter in length from the sensor. Then, it crossed the chamber through the bushing and it was connected to the interrogator unit. As a reference, a PCB Piezotronic uniaxial accelerometer model $352 \mathrm{C} 34$ with a sensitivity of $100 \mathrm{mV} / \mathrm{g}$ and a resonance frequency higher than $50 \mathrm{kHz}$ 
was located at the same support. The piezoelectric sensor was read from a LMS Scada SCR 05 to a sample rate of $1000 \mathrm{~Hz}$. The same acquisition system was used to generate a sine wave to drive a shaker model The Modal Shop 2025E. This shaker allowed applying a force level of $58 \mathrm{~N}$.

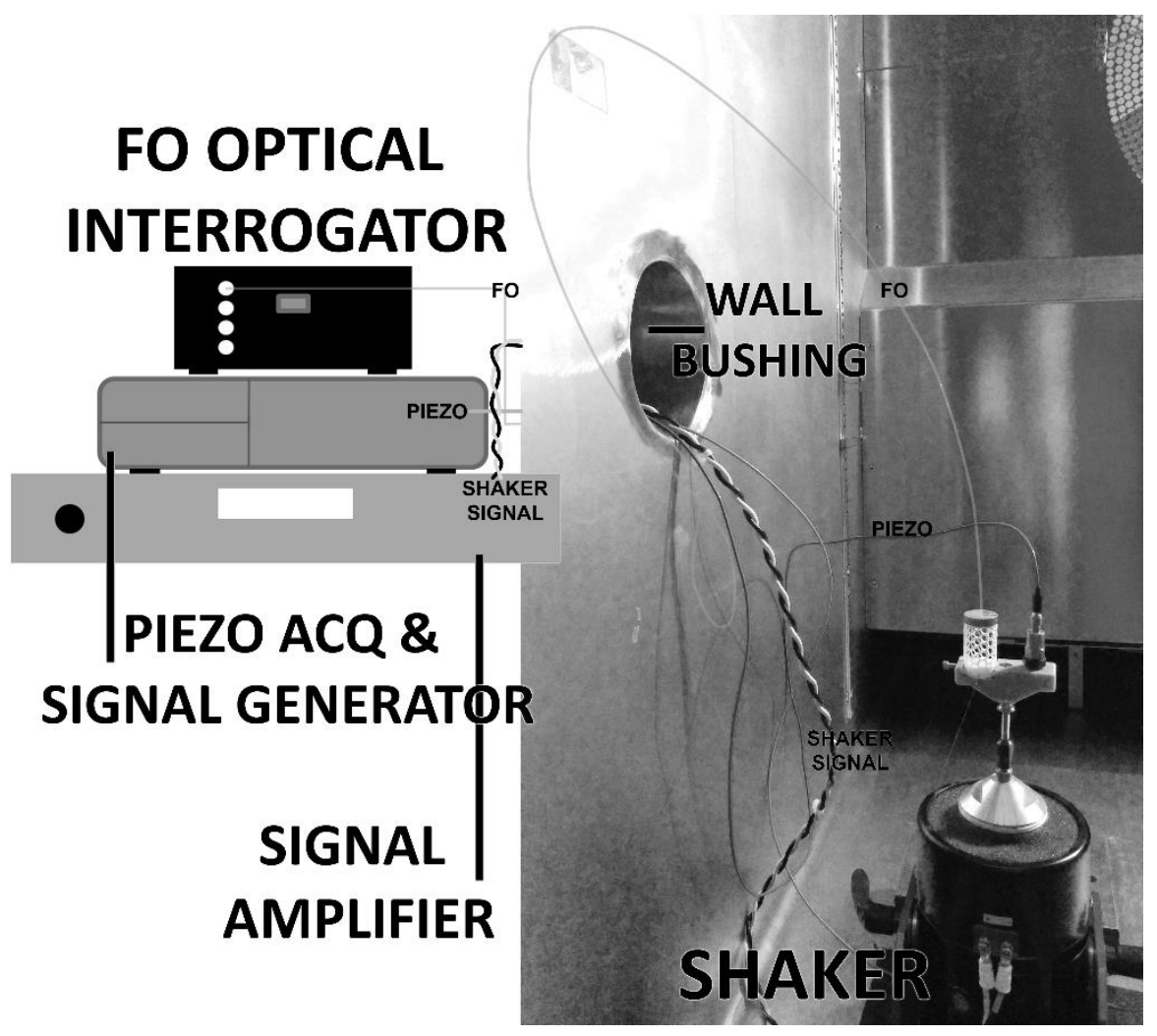

Figure 4. Set-up of FO accelerometer in characterization tests: support with piezoelectric sensor, FO optical interrogator, piezoelectric acquisition and signal generator, signal amplifier and shaker.

For sensitivity characterization of the FBG accelerometer, harmonic forces were applied at the frequencies [10, 25:25:475] Hz. The highest frequency was set accounting for the expected linear frequency range of the FBG sensor computed by the numerical model and the maximum sample rate of the acquisition system. At each frequency, the shaker generated 10 seconds of harmonic excitation for amplitudes of $0.5,1,2,3,4 \mathrm{~g}$. The signal for each step of intensity and frequency was conditioned and filtered with high-pass and low-pass third-order Chebyshev filters of $5 \mathrm{~Hz}$ and $495 \mathrm{~Hz}$, respectively. Then, a Fast Fourier Transform (FFT) algorithm was applied to the time domain signals. For each frequency and intensity, the Frequency Response Function (FRF) was calculated as the 
ratio between the signals of the FBG (output) and piezoelectric (input) accelerometers. Figure 5 shows the wavelength amplitudes recorded at 10, 25, 75, 100, 200, 300 and $475 \mathrm{~Hz}$ for all the intensity levels. The FBG accelerometer behaved linearly at all tested frequencies with regression coefficients higher than 0.99 .

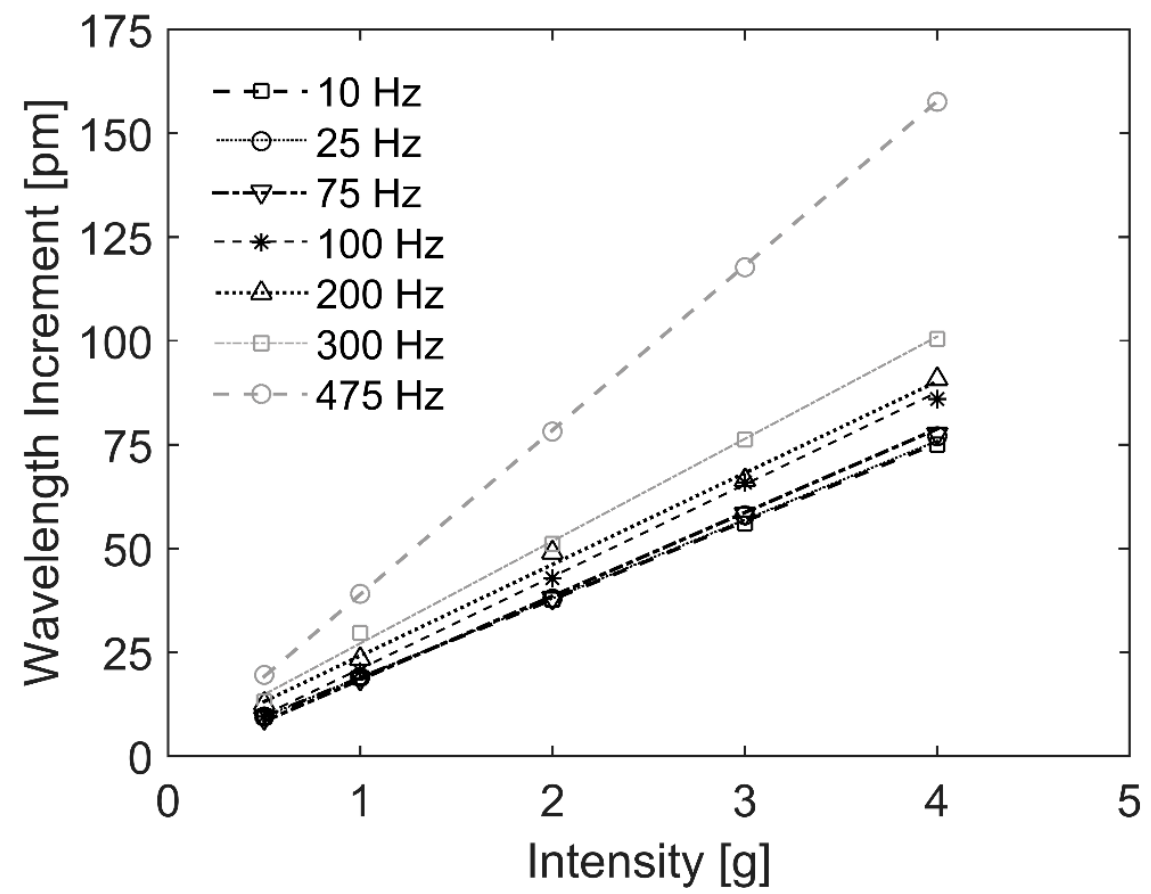

Figure 5. FBG accelerometer wavelength amplitude: experimental (circles) and regression approaches (lines).

Figure 6 shows the sensitivity computed as the slope of these curves at each frequency. Numerical results perfectly agree with the response of a 1DOF system as it was expected. The accelerometer sensitivity was analysed for several intensities in the frequency range 10-475 Hz. Figure 6.(a) shows that the sensitivity at low frequency presented a value of $19.29 \mathrm{pm} / \mathrm{g}$ and it gradually increased up to $34.45 \mathrm{pm} / \mathrm{g}$ at $475 \mathrm{~Hz}$. From this frequency, the sensitivity increases rapidly up to the resonance. The agreement between experimental and numerical values was quite good with small deviations lower than $2.4 \mathrm{pm} / \mathrm{g}$ in the vicinity of $150 \mathrm{~Hz}$, probably due to the bending frequencies of the system (136 and $137 \mathrm{~Hz}$ ). Therefore, the design of the accelerometer should consider the negative effect of the bending mode shapes on the frequency response function increasing the bending stiffness. In the proposed accelerometer, this effect could be reduced enclosing the sensor by a slightly higher diameter cylinder or installing some auxiliary bars to the lattice structure in order to increase the lateral stiffness. The maximum deviation was registered 
at $475 \mathrm{~Hz}$ with a value of $4.51 \mathrm{pm} / \mathrm{g}$. A statistical analysis of the data presented in Figure 6.(a) reveals mean $(\mu)$ and standard deviation $(\sigma)$ values of 23.52 and $5.36 \mathrm{pm} / \mathrm{g}$, respectively. The sensitivities obtained from all tests, except at $475 \mathrm{~Hz}$, were in the area defined by $\mu \pm 2 \sigma$.

Accelerometers are used in their linear behaviour range, commonly accepted as a third of their resonance frequency. The developed sensor presented a usable region up to $236 \mathrm{~Hz}$, in which the mean sensitivity and the standard deviation were 19.65 and $1.28 \mathrm{pm} / \mathrm{g}$, respectively (Figure 6.(b)). The measurements obtained from all tests in the linear range were inside the area defined by the mean and twice the standard deviation.
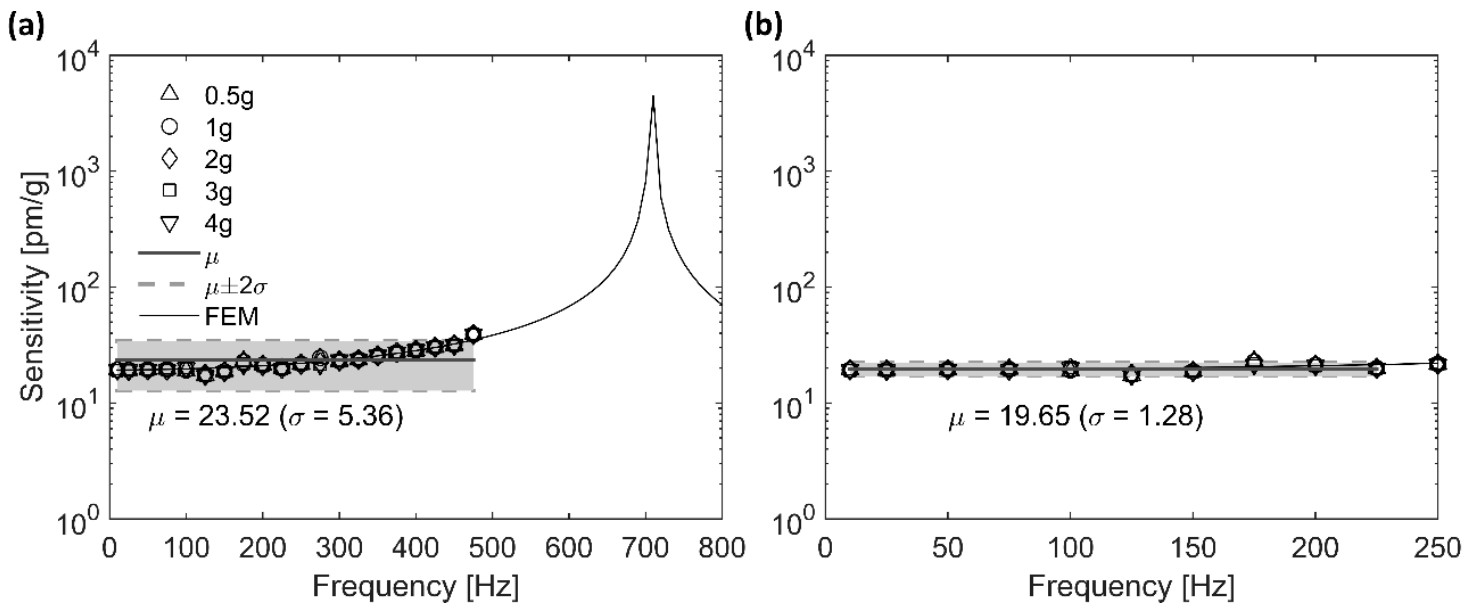

Figure 6. (a) $0-800 \mathrm{~Hz}$ and (b) $0-236 \mathrm{~Hz}$ (linear response) FBG accelerometer sensitivity: experimental data (markers), mean (thick line) and numerical result (thin line). A grey area limited by twice the standard deviation is superimposed.

The uncertainties of this calibration process could be due to: (i) repeatability and stability of the fibre reading equipment ( 1 and $2 \mathrm{pm}$, respectively); (ii) variability of the final properties of the lattice cylinder due to the powder quality and AM machine parameters; (iii) repeatability and stability of shaker, signal amplifier, signal generator and reference piezoelectric accelerometer and (iv) dynamic properties of the auxiliary tools used to support the accelerometers.

\section{STRUCTURAL TESTS AND RESULTS}

Next, the results of a case study are presented. Modal analysis of the wing of a UAV was carried out by several sensors. The wing was manufactured with a foam core, a layer of GFRP (Glass Fibre Reinforced Plastic) and two extra layers of CFRP (Carbon Fibre 
Reinforced Plastic). The full wing geometric characteristics are $1300 \mathrm{~mm}$ length, $2000 \mathrm{~mm}$ span, a mean chord of $285 \mathrm{~mm}$ (with $335 \mathrm{~mm}$ root and $250 \mathrm{~mm}$ tip chord), sweep and dihedral angles of $2.3^{\circ}$ and $2^{\circ}$, respectively, taper ratio 0.75 and airfoil maximum thickness of $45 \mathrm{~mm}$.

Five FBGs were embedded between the GFRP and the CFRP layers for measuring strain at locations indicated in Figure 7. Figure 8 shows the experimental set-up. The FO accelerometer was placed at the free end by a plastic support. Moreover, for comparison purposes, the same piezoelectric accelerometer used in the characterization tests and three triaxial low-cost MEMS sensors were added to the same support. Two of these MEMS were model ADXL 335 with a nominal sensitivity of $300 \mathrm{mV} / \mathrm{g}$. The third one was a digital model ADXL 345 with a sensitivity of approximately $32 \mathrm{LSB} / \mathrm{g}$ in the configuration used in these tests.

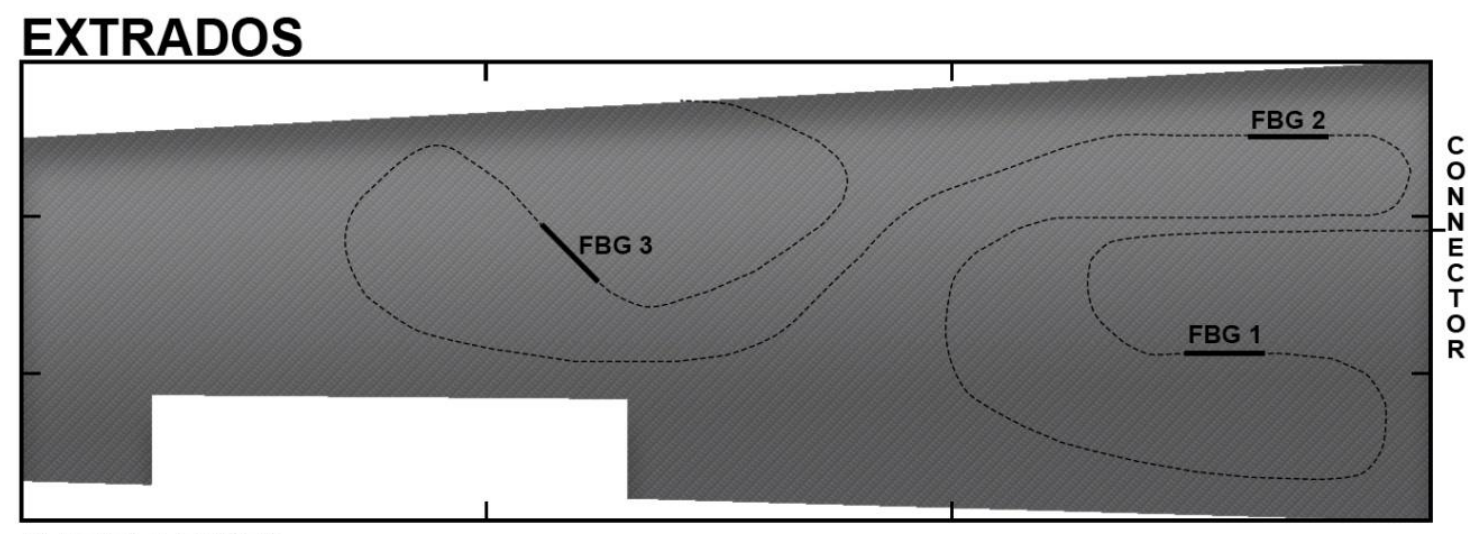

\section{INTRADOS}

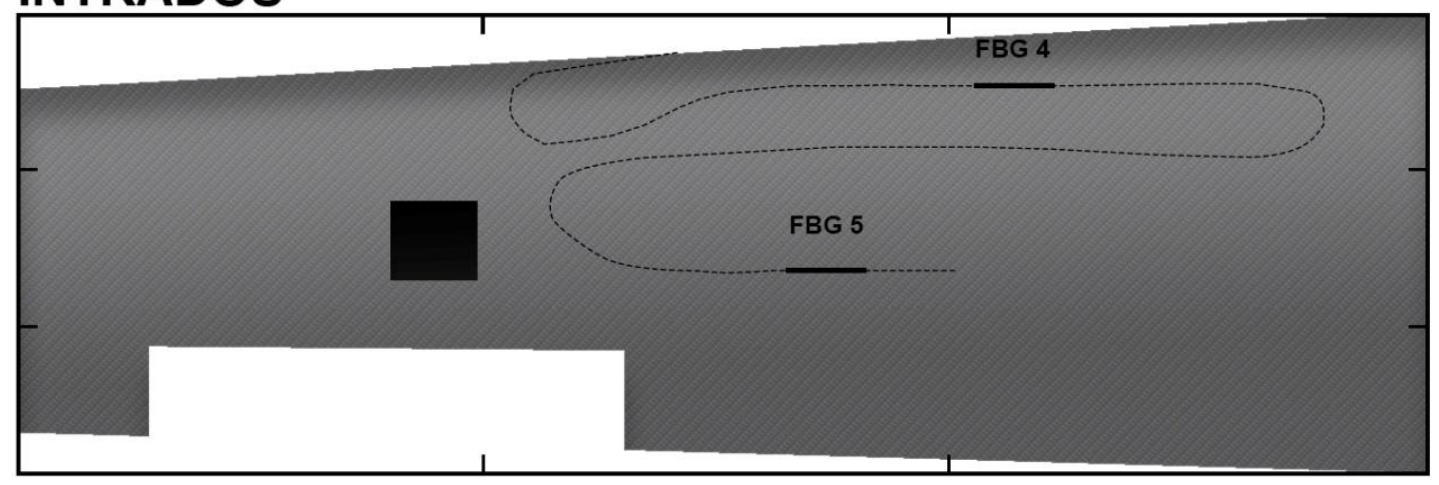

Figure 7. Wing schematic view from extrados and intrados: FBG sensors locations (wide continue lines) and FO path (dashed line). 


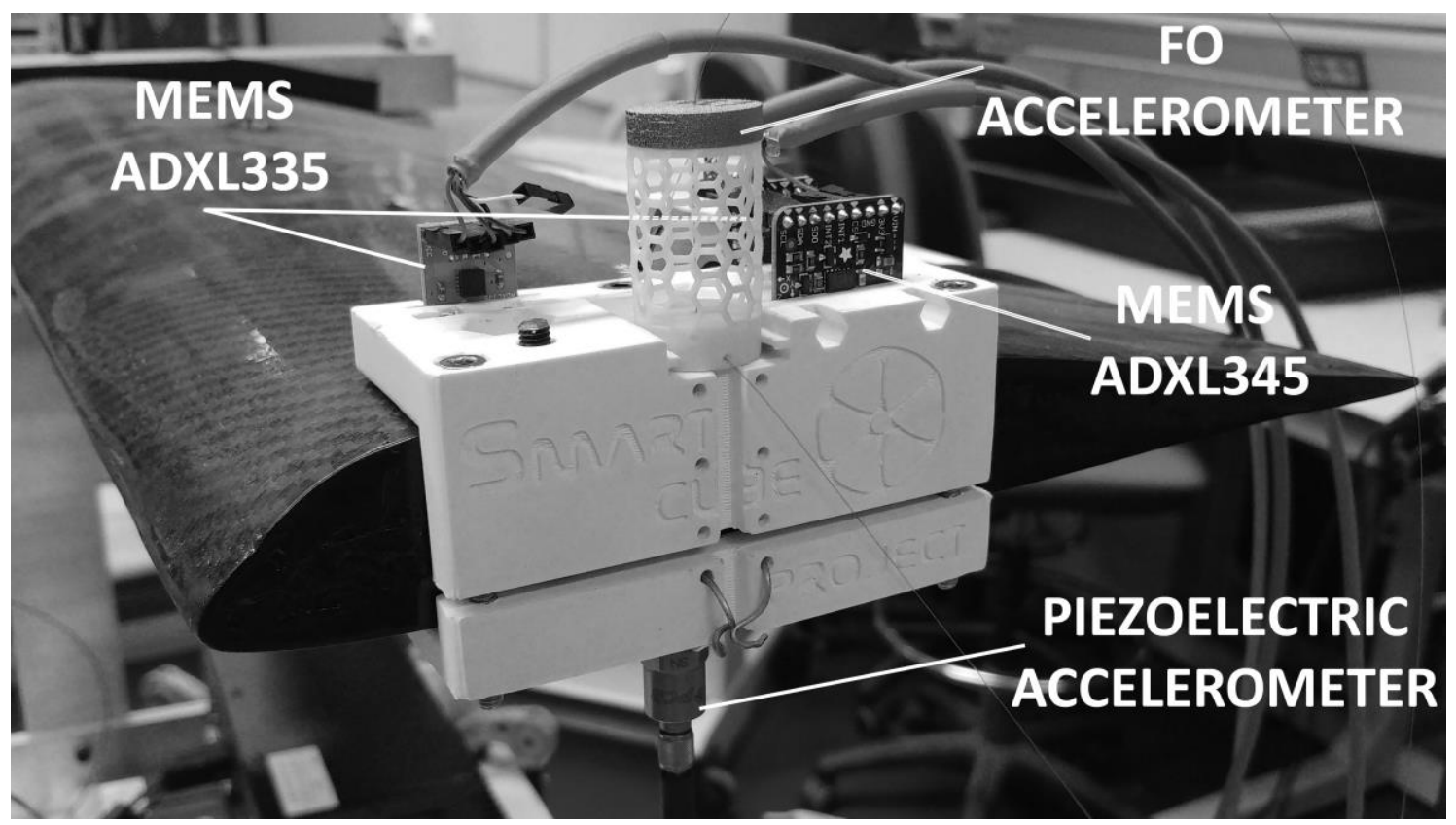

Figure 8. Experimental set-up: FO, piezo electric, MEMS ADXL335 and MEMS ADXL345 accelerometers.

A hammer model PCB 086C04 equipped with a hard metal tip was used in all tests. Three scenarios were tested. The wing responses due to 5 impacts were recorded in each scenario. In the first scenario, the impacts were applied at $240 \mathrm{~mm}$ from the wing root. In the second one at $500 \mathrm{~mm}$ from the root, that is, practically at the centre. Finally, in the third scenario, the impacts were applied close to the tip, at $780 \mathrm{~mm}$ from the root.

The MEMS sensors' signals were acquired by a specific script under Arduino DUE at a sampling frequency of $400 \mathrm{~Hz}$. The FO sensors (accelerometer embedded) signals were acquired at a sampling frequency of $1000 \mathrm{~Hz}$. Both previously indicated sampling rates were limited by the data acquisition systems. The responses of the piezoelectric sensors were also sampled at $1000 \mathrm{~Hz}$.

The first step in the post-processing was decimating the signals from the piezoelectric (accelerometer and hammer) and FO sensors to $400 \mathrm{~Hz}$. The second step was computing the frequency responses by the FFT algorithm. The strain measured by the embedded sensors were transformed to acceleration: the strain values were multiplied by the length of the sensor and the angular frequency to the second power. Then, FRF was obtained as the ratio between the signal from the hammer (input) and the sensor responses (output) in the frequency domain accounting for the mean value of the five impacts. Finally, the 
coherence function was used to determine whether the responses were affected by noise or nonlinearities. The coherence function was calculated according to Eq. 9:

$$
\text { Coherence }(f)=\sum_{\text {test }=1}^{5}\left(\operatorname{abs}\left(R(f) \cdot H^{*}(f)\right)\right)^{2} / \sum_{\text {test }=1}^{5} a b s(H(f))^{2} \cdot \sum_{\text {test }=1}^{5} a b s(R(f))^{2}
$$

where $R(f)$ stands for the frequency response of the sensor and $H(f)$ is the frequency response of the hammer. The asterisk means complex conjugate value. The measurements were considered acceptable when coherence values were close to 1 .

Figures 9-11 show the FRF and the coherence functions obtained in the three scenarios. For the scenario 1 (Figure 9), all the sensors, except FBG4 and FBG5, show clearly three peaks at $10.25,23.25$ and $115.8 \mathrm{~Hz}$. Maximum values about 20,15 and $10 \mathrm{~ms}^{-2} / \mathrm{N}$ were measured at the third of these peaks by the FO, the piezoelectric and the digital MEMS accelerometers, respectively. The analogical MEMS accelerometers and the FO embedded sensors measured levels about 2.5 and $1 \mathrm{~ms}^{-2} / \mathrm{N}$, respectively. The differences between the measured values could be explained accounting for the sensors were not at exactly the same location. The coherence of the piezoelectric sensor was higher than 0.95 in the frequency range. The coherence computed from the FO accelerometer was around 0.75 with a minimum of 0.4 at $68 \mathrm{~Hz}$. The MEMS accelerometers presented a lower coherence. FBG4 and FBG5 embedded sensors gave high coherence values between 25 and $130 \mathrm{~Hz}$. FBG1, FBG2 and FBG3 showed an irregular behaviour.

Figure 10 shows the results for the scenario 2 (impacts applied close to the wing centre). Resonance frequencies at $10.25,23.25$ and $115.8 \mathrm{~Hz}$ were again identified. The relation between the levels measured from each sensor was approximately as in the Figure 9, being $25 \mathrm{~ms}^{-2} / \mathrm{N}$ the higher value from the FO accelerometer. The coherence computed by the signal from the piezoelectric accelerometer was practically one, except at $175 \mathrm{~Hz}$ where it decreased to 0.8 . The FO accelerometer coherence function presented a minimum at around $60 \mathrm{~Hz}$. The MEMS showed an irregular behaviour in all the frequency range. The embedded sensor coherence functions were as in the scenario 1 . 

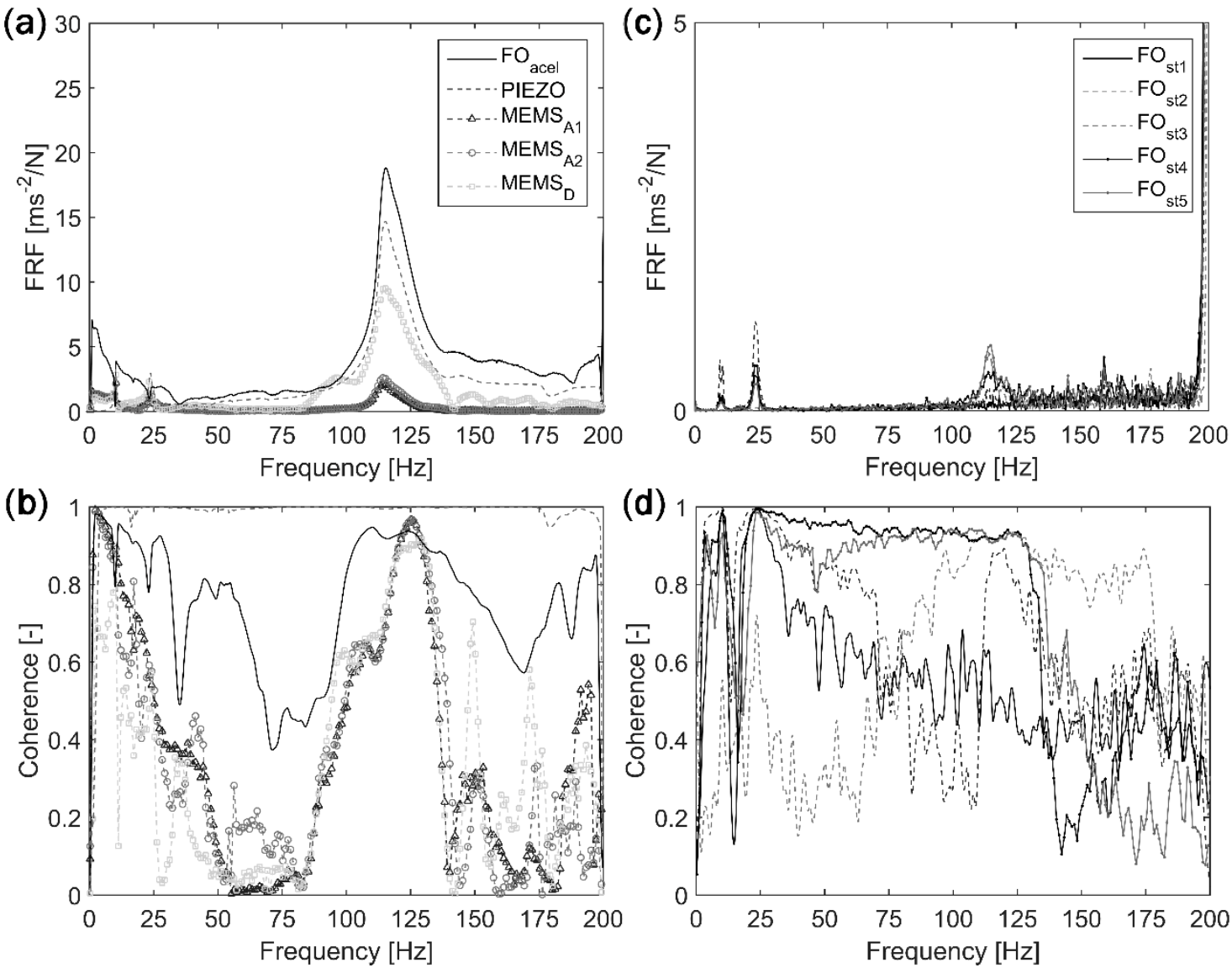

Figure 9. $(a, c)$ FRF and $(b, d)$ coherence function obtained in scenario 1: $(a, b)$ FO, piezoelectric and MEMS accelerometers and (c,d) embedded sensors.

Figure 11 shows the results for the scenario 3 (impacts close to the wing tip). The peak at $115 \mathrm{~Hz}$ was not identified from the measurements since the impact position matched with a node of this mode. The levels recorded by the embedded sensors were higher in this case. Piezoelectric and FO accelerometers, and embedded sensors measured acceptable values of the coherence function. However, the MEMS were very unstable. 

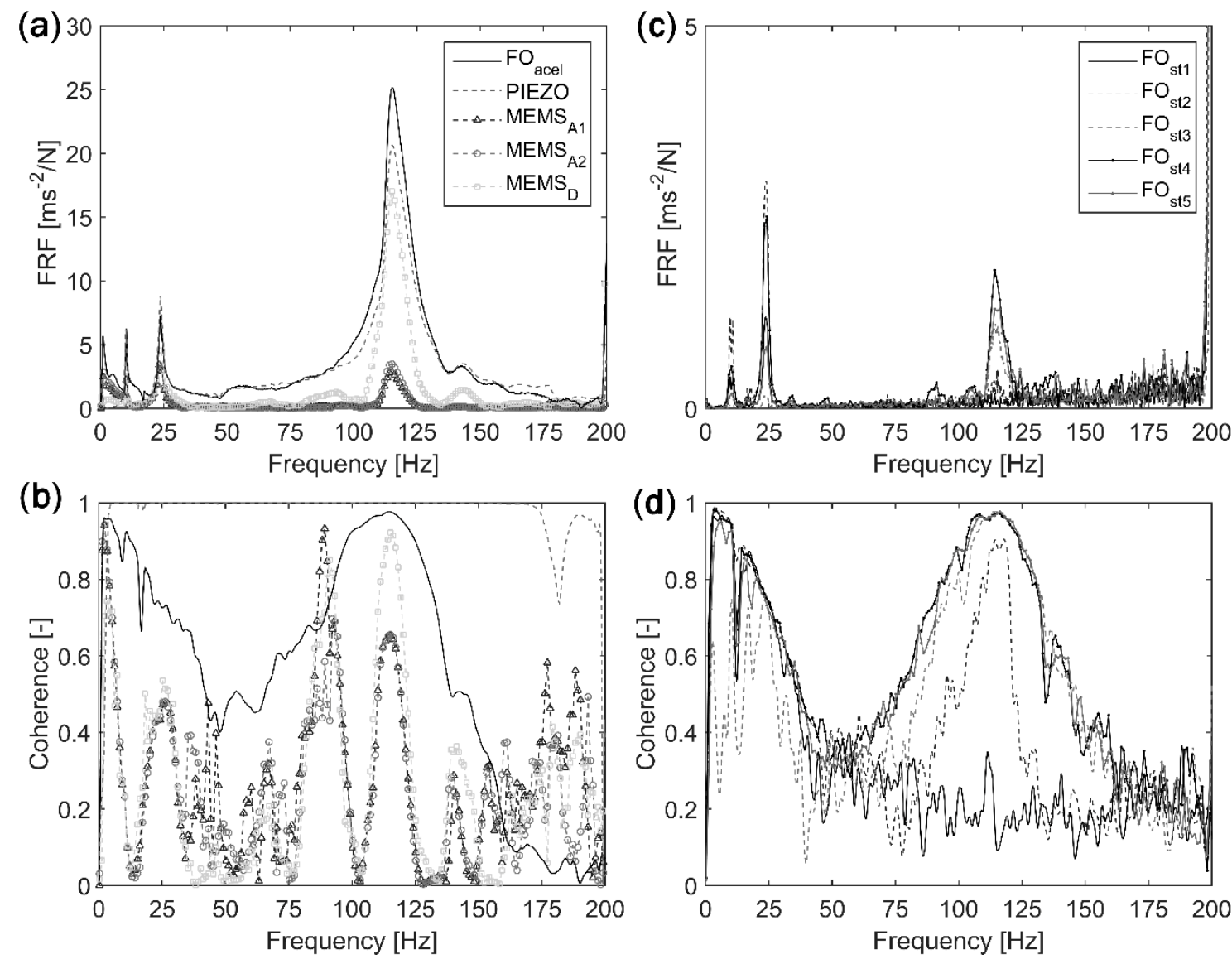

Figure 10. $(a, c)$ FRF and $(b, d)$ coherence function obtained in scenario 2: $(a, b)$ FO, piezoelectric and MEMS accelerometers and (c,d) embedded sensors.

The highest value of the coherence function was measured by the piezoelectronic accelerometer in each scenario with values close to one. FO designed accelerometer presented a good performance with coherence values about 0.8 at the frequency ranges from 0 to $25 \mathrm{~Hz}$ and from 90 to $130 \mathrm{~Hz}$. Embedded sensors FBG4 and FBG5 showed a response similar to the FO accelerometer. However, the coherence functions measured by FBG1, FBG2 and FBG3 sensors were below to 0.8. The MEMS sensors had an irregular behaviour in all the tests. These sensors were the cheapest and their signals were acquired by a home-built Arduino DUE system. 

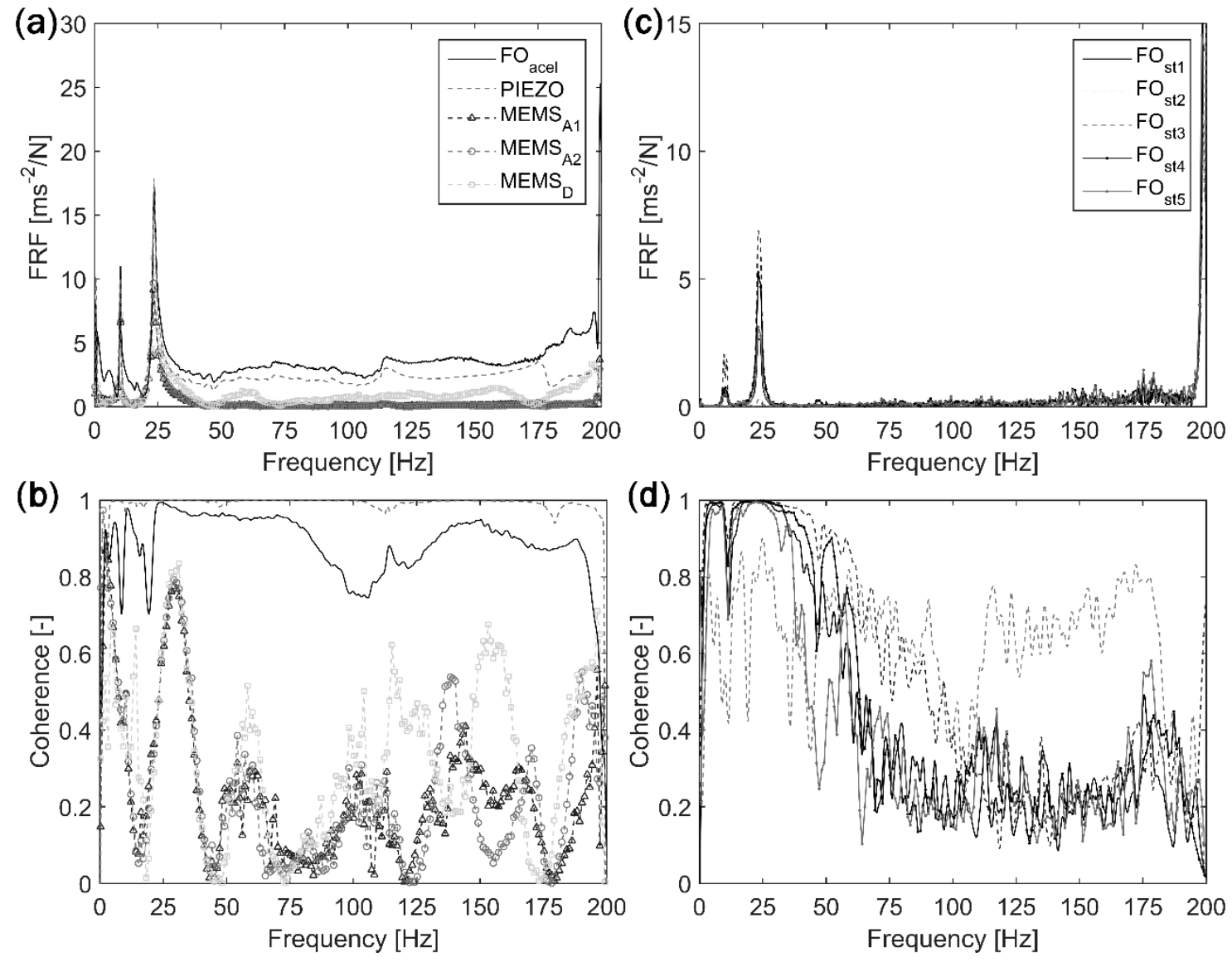

Figure 11. $(a, c)$ FRF and $(b, d)$ coherence function obtained in scenario $3:(a, b)$ FO, piezoelectric and MEMS accelerometers and (c,d) embedded sensors.

\section{CONCLUSIONS}

In aerospace industry, weight reduction is critical for achieving engineering or financial objectives. Hence, the use of low weight sensors is convenient for on-board installation, even more if a large number of them is placed. To assess the structural integrity of aircrafts, which are continually subjected to dynamic loadings, accelerometers and strain sensors should be used for studying dynamic and static responses. Response from accelerometers can be useful to detect impacts or any type of sudden load events.

The developed FBG accelerometer has many advantages as low weight ( 9.19 grams), low volume $(20 \mathrm{~mm}$ diameter and $30 \mathrm{~mm}$ long), nominal sensitivity $(19.65 \mathrm{pm} / \mathrm{g})$ and a resonance frequency of $708 \mathrm{~Hz}$. The sensor has presented a linear behaviour quite acceptable with regression coefficients higher than 0.99 . The results presented have demonstrated the FBG accelerometer behaviour is similar to the piezoelectric sensor. The measured responses have been better that those from MEMS and FBG embedded sensors. Moreover, the developed accelerometer could have a competitive price for the production 
of a low number of sensors. Approximately, the price could be around $70 €$, being the Bragg gratings the most expensive component with a price about $50 €$.

The work in progress focuses on reducing the size and the weight of the sensor using gratings with smaller sensor longitude and increasing the bending stiffness to decrease the transverse sensitivity. Combined sensors based on the same concept could also be very interesting as a future development.

\section{ACKNOWLEDGEMENTS}

The authors wish to thank the division of Materials \& Processes of FADA-CATEC for the economic support to develop this work and especially to Borja Rodríguez for his advice and help in additive manufacturing. Big thanks go also to Carmen Curiel regarding the FEM modelling and results.

Prof. Galvín would like to acknowledge the financial support provided by the Spanish Ministry of Economy and Competitiveness (Ministerio de Economía y Competitividad) under the research projects [BIA2013-43085-P and BIA2016-75042-C2-1-R].

\section{REFERENCES}

[1] SAE, SAE ARP 6461 Standard - Guidelines for Implementation of Structural Health Monitoring on Fixed Wing Aircraft, (2013) 95.

[2] H. Sohn, C.R.C.R. Farrar, N.F.N.F. Hunter, K. Worden, Structural Health Monitoring Using Statistical Pattern Recognition Techniques, J. Dyn. Syst. Meas. Control. 123 (2001) 706. doi:10.1115/1.1410933.

[3] P. Moyo, J.M.W. Brownjohn, R. Suresh, S.C. Tjin, Development of fiber Bragg grating sensors for monitoring civil infrastructure, Eng. Struct. 27 (2005) 18281834. doi:10.1016/j.engstruct.2005.04.023.

[4] A. Othonos, K. Kalli, Fiber Bragg gratings: fundamentals and applications in telecommunications and sensing, Artech House, 1999.

[5] R. Yun-Jiang, In-fibre Bragg grating sensors, Meas. Sci. Technol. 8 (1997) 355375. doi:10.1088/0957-0233/8/4/002.

[6] K.O. Hill, G. Meltz, Fiber Bragg grating technology fundamentals and overview, J. Light. Technol. 15 (1997) 1263-1276. doi:10.1109/50.618320.

[7] J. Güemes, J. Menendez, M. Frövel, I. Fernandez, J. Pintado, Experimental analysis of buckling in aircraft skin panels by fibre optic sensors, Smart Mater. Struct. 10 (2001) 490-496. doi:S0964-1726(01)22805-5.

[8] G. Pereira, C. Frias, H. Faria, O. Frazão, A.T. Marques, On the improvement of strain measurements with FBG sensors embedded in unidirectional composites, Polym. Test. 32 (2013) 99-105. doi:10.1016/j.polymertesting.2012.09.010.

[9] G. Luyckx, E. Voet, N. Lammens, J. Degrieck, Strain measurements of composite laminates with embedded fibre bragg gratings: Criticism and opportunities for research, Sensors. 11 (2011) 384-408. doi:10.3390/s110100384.

[10] R. Fernandez, N. Gutierrez, H. Jimenez, F. Martin, L. Rubio, J.D. Jimenez-Vicaria, C. Paulotto, F. Lasagni, On the Structural Testing Monitoring of CFRP Cockpit and Concrete/CFRP Pillar by FBG Sensors, Adv. Eng. Mater. 18 (2016) 12891298. doi:10.1002/adem.201600065.

[11] K. Chandler, S. Ferguson, T. Graver, A. Csipkes, A. Mendez, On-line structural health and fire monitoring of a composite personal aircraft using an FBG sensing 
system., in: Proc. SPIE, 2008: p. 69330H, 6p. doi:10.1117/12.783125.

[12] R. Maaskant, T. Alavie, R.M. Measures, G. Tadros, S.H. Rizkalla, a. GuhaThakurta, Fiber-optic Bragg grating sensors for bridge monitoring, Cem. Concr. Compos. 19 (1997) 21-33. doi:10.1016/S0958-9465(96)00040-6.

[13] R. Di Sante, L. Donati, Strain monitoring with embedded Fiber Bragg Gratings in advanced composite structures for nautical applications, Meas. J. Int. Meas. Confed. 46 (2013) 2118-2126. doi:10.1016/j.measurement.2013.03.009.

[14] R. Di Sante, Fibre Optic Sensors for Structural Health Monitoring of Aircraft Composite Structures: Recent Advances and Applications., Sensors (Basel). 15 (2015) 18666-713. doi:10.3390/s150818666.

[15] S. Gupta, T. Mizunami, T. Yamao, T. Shimomura, Fiber Bragg grating cryogenic temperature sensors., Appl. Opt. 35 (1996) 5202-5. doi:10.1364/AO.35.005202.

[16] S. Pal, T. Sun, K.T. V Grattan, S.A. Wade, S.F. Collins, G.W. Baxter, B. Dussardier, G. Monnom, Non-linear temperature dependence of Bragg gratings written in different fibres, optimised for sensor applications over a wide range of temperatures, Sensors Actuators, A Phys. 112 (2004) 211-219. doi:10.1016/j.sna.2004.01.024.

[17] N.A. Mohammed, T.A. Ali, M.H. Aly, Evaluation and performance enhancement for accurate FBG temperature sensor measurement with different apodization profiles in single and quasi-distributed DWDM systems, Opt. Lasers Eng. 55 (2014) 22-34. doi:10.1016/j.optlaseng.2013.10.013.

[18] D. Kinet, D. Garray, P. Mégret, C. Caucheteur, Temperature and strain effects discrimination inside composite materials with embedded weakly tilted fibre Bragg grating, 5th Eur. Work. Opt. Fibre Sensors, EWOFS 2013. 8794 (2013) 16. doi:10.1117/12.2025841.

[19] M.L. Filograno, C. Chluda, D. Kinet, C. Caucheteur, P. Corredera, P. Mégret, Temperature and Strain Effects Discrimination Into Composite Materials With Embedded Dual Type I-Ia Fibre Bragg Gratings, in: Proc. 15th Eur. Conf. Compos. Mater., Venice, 2012: pp. 24-28.

[20] S. Triollet, L. Robert, E. Marin, Y. Ouerdane, Discriminated measures of strain and temperature in metallic specimen with embedded superimposed long and short fibre Bragg gratings, Meas. Sci. Technol. 22 (2011) 15202. doi:10.1088/09570233/22/1/015202.

[21] H.S. Kim, S.H. Yoo, S.H. Chang, In situ monitoring of the strain evolution and curing reaction of composite laminates to reduce the thermal residual stress using FBG sensor and dielectrometry, Compos. Part B Eng. 44 (2013) 446-452. doi:10.1016/j.compositesb.2012.04.021.

[22] G. Chiesura, A. Lamberti, Y. Yang, G. Luyckx, W. Van Paepegem, S. Vanlanduit, J. Vanfleteren, J. Degrieck, RTM production monitoring of the A380 hinge armdroop nose mechanism: A multi-sensor approach, Sensors (Switzerland). 16 (2016) 1-17. doi:10.3390/s16060866.

[23] A.D. Kersey, M.A. Davis, H.J. Patrick, M. LeBlanc, K.P. Koo, C.G. Askins, M.A. Putnam, E.J. Friebele, Fiber grating sensors, J. Light. Technol. 15 (1997) 14421463. doi:10.1109/50.618377.

[24] R. Measures, S. Abrate, Structural Monitoring with Fiber Optic Technology, Academic Press, 2002. doi:10.1115/1.1445327.

[25] S.R.K. Morikawa, A.S. Ribeiro, R.D. Regazzi, L.C.G. Valente, A.M.B. Braga, Triaxial Bragg grating accelerometer, 2002 15th Opt. Fiber Sensors Conf. Tech. Dig. OFS 2002. (2002) 95-98. doi:10.1109/OFS.2002.1000510.

[26] A. Fender, W.N. MacPherson, R.R.J. Maier, J.S. Barton, D.S. George, R.I. 
Howden, G.W. Smith, B.J.S. Jones, S. McCulloch, X. Chen, R. Suo, L. Zhang, I. Bennion, Two-axis temperature-insensitive accelerometer based on multicore fiber Bragg gratings, IEEE Sens. J. 8 (2008) 1292-1298. doi:10.1109/JSEN.2008.926878.

[27] Y. Zhang, X. Qiao, Q. Liu, D. Yu, H. Gao, M. Shao, X. Wang, Study on a fiber Bragg grating accelerometer based on compliant cylinder, Opt. Fiber Technol. 26 (2015) 229-233. doi:10.1016/j.yofte.2015.09.011.

[28] Y. Guozhen, L. Yongqian, Y. Zhi, A novel fiber Bragg grating acceleration sensor for measurement of vibration, Opt. - Int. J. Light Electron Opt. 127 (2016) 88748882. doi:10.1016/j.ijleo.2016.06.105.

[29] P.F.C. Antunes, C.A. Marques, H. Varum, P.S. Andrél, Biaxial optical accelerometer and high-angle inclinometer with temperature and cross-axis insensitivity, IEEE Sens. J. 12 (2012) 2399-2406. doi:10.1109/JSEN.2012.2190763.

[30] Q. Liu, X. Qiao, Z. Jia, H. Fu, H. Gao, D. Yu, Large Frequency Range and High Sensitivity Fiber Bragg Grating Accelerometer Based on Double Diaphragms, IEEE Sens. J. 14 (2014) 1499-1504. doi:10.1109/JSEN.2013.2296932.

[31] Q. Jiang, M. Yang, A high sensitivity vector accelerometer based on tri-axial fiber Bragg grating, Opt. Appl. 42 (2012) 901-912. doi:10.5277/oa120421.

[32] Y. Dai, G. Yin, B. Liu, G. Xu, J.M. Karanja, Medium-high frequency FBG accelerometer with integrative matrix structure, Appl. Opt. 54 (2015) 3115-3121.

[33] J. Wang, G. Peng, Z. Hu, H. Yang, Y. Hu, Design and analysis of a high sensitivity FBG accelerometer based on local strain amplification, IEEE Sens. J. 15 (2015) 5442-5449. doi:10.1109/JSEN.2014.2370640.

[34] L. Sun, Y. Shen, C. Cao, A novel FBG-based accelerometer with high sensitivity and temperature self-compensation, in: Proc. SPIE, 2009: pp. 729214-729214-10. doi: $10.1117 / 12.815579$.

[35] S. Thériault, K.O. Hill, F. Bilodeau, D.C. Johnson, J. Albert, G. Drouin, A. Béliveau, High-g accelerometer based on an In-Fiber Bragg Grating Sensor, Opt. Rev. 4 (1997) 145-147. doi:10.1007/BF02936013.

[36] J.M. López-Higuera, M.A. Morante, A. Cobo, Simple Low-Frequency Optical Fiber Accelerometer with Large Rotating Machine Monitoring, J. Light. Technol. 15 (1997) 1120-1130. doi:10.1109/50.596957.

[37] P.F. Costa Antunes, H.F.T. Lima, N.J. Alberto, H. Rodrigues, P. Fernando, H. Rodrigues, P.M.F. Pinto, J.D.L. Pinto, R.N. Nogueira, H. Varum, A.G. Costa, P.S. Brito André, Optical Fiber Accelerometer System for Structural Dynamic Monitoring, IEEE Sens. J. 11 (2009) 1347-1354. doi:10.1109/JSEN.2009.2026548.

[38] P. Antunes, H. Varum, P. André, Uniaxial fiber Bragg grating accelerometer system with temperature and cross axis insensitivity, Measurement. 44 (2011) 5559. doi:10.1016/j.measurement.2010.09.013.

[39] J. Wang, B. Hu, W. Li, G. Song, L. Jiang, T. Liu, Design and application of fiber Bragg grating (FBG) geophone for higher sensitivity and wider frequency range, Meas. J. Int. Meas. Confed. 79 (2016) 228-235. doi:10.1016/j.measurement.2015.09.041.

[40] M. Mansoor Khan, N. Panwar, R. Dhawan, Modified cantilever beam shaped FBG based accelerometer with self temperature compensation, Sensors Actuators A. Phys. 205 (2014) 79-85. doi:10.1016/j.sna.2013.10.027.

[41] Q. Liu, Z. Jia, H. Fu, D. Yu, H. Gao, X. Qiao, Double Cantilever Beams Accelerometer Using Short Fiber Bragg Grating for Eliminating Chirp, IEEE Sens. 
J. 16 (2016) 6611-6616. doi:10.1109/JSEN.2016.2588485.

[42] N. Basumallick, P. Biswas, R. Chakraborty, S. Chakraborty, K. Dasgupta, S. Bandyopadhyay, Fibre Bragg grating based accelerometer with extended bandwidth, Meas. Sci. Technol. 27 (2016) 35008. doi:10.1088/09570233/27/3/035008.

[43] G.N. Levy, R. Schindel, J.P. Kruth, Rapid Manufacturing and Rapid Tooling With Layer Manufacturing (Lm) Technologies, State of the Art and Future Perspectives, CIRP Ann. - Manuf. Technol. 52 (2003) 589-609. doi:10.1016/S00078506(07)60206-6.

[44] J.-P. Kruth, M.C. Leu, T. Nakagawa, Progress in Additive Manufacturing and Rapid Prototyping, CIRP Ann. - Manuf. Technol. 47 (1998) 525-540. doi:10.1016/S0007-8506(07)63240-5.

[45] ASTM International, F2792-12a - Standard Terminology for Additive Manufacturing Technologies, Rapid Manuf. Assoc. (2013) 10-12. doi:10.1520/F2792-12A.2.

[46] S.H. Huang, P. Liu, A. Mokasdar, L. Hou, Additive manufacturing and its societal impact: A literature review, Int. J. Adv. Manuf. Technol. 67 (2013) 1191-1203. doi:10.1007/s00170-012-4558-5.

[47] W.E. Frazier, Metal additive manufacturing: A review, J. Mater. Eng. Perform. 23 (2014) 1917-1928. doi:10.1007/s11665-014-0958-z.

[48] S.S. Crump, Fast, precise, safe prototypes with FDM, ASME, PED. 50 (1991) 5360.

[49] J.J. Beaman, J.W. Barlow, D.L. Bourell, R.H. Crawford, H.L. Marcus, K.P. McAlea, Solid freeform fabrication: A new Direction in Manufacturing, Springer, 1997. doi:10.1007/978-1-4615-6327-3.

[50] C. Deckard, J.J. Beaman, Process and control issues in selective laser sintering, ASME Prod Eng Div PED. 33 (1988) 191-197.

[51] T. Erdogan, Fiber grating spectra, J. Light. Technol. 15 (1997) 1277-1294. doi:10.1109/50.618322.

[52] R. Di Sante, L. Donati, E. Troiani, P. Proli, Evaluation of bending strain measurements in a composite sailboat bowsprit with embedded fibre Bragg gratings, Meas. J. Int. Meas. Confed. 54 (2014) 106-117. doi:10.1016/j.measurement.2014.04.019.

[53] A. Derkevorkian, S.F. Masri, J. Alvarenga, H. Boussalis, J. Bakalyar, W.L. Richards, Strain-Based Deformation Shape-Estimation Algorithm for Control and Monitoring Applications, AIAA J. 51 (2013) 2231-2240. doi:10.2514/1.J052215.

[54] A. Bertucci, A. Mornacchi, G. Jacazio, M. Sorli, A Force Control Test Rig for the Dynamic Characterization of Helicopter Primary Flight Control Systems, Procedia Eng. 106 (2015) 71-82. doi:10.1016/j.proeng.2015.06.010.

[55] M.C. Faustini, R.R. Neptune, R.H. Crawford, S.J. Stanhope, Manufacture of passive dynamic ankle-foot orthoses using selective laser sintering, IEEE Trans. Biomed. Eng. 55 (2008) 784-790. doi:10.1109/TBME.2007.912638.

[56] J.Y. Taillon, F. Légeron, S. Prud'Homme, Variation of damping and stiffness of lattice towers with load level, J. Constr. Steel Res. 71 (2012) 111-118. doi:10.1016/j.jcsr.2011.10.018.

[57] A. Mita, I. Yokoi, Fiber Bragg grating accelerometer for structural health monitoring, in: Conf. Motion Vib. Control (MOVIC 2000), Sydney, 2000. http://www.mita.sd.keio.ac.jp/publications/data/d200005.pdf\%5Cnpapers3://publ ication/uuid/78CF2EDE-76F8-4C0A-ACEB-692A0A720561.

[58] A. Mita, I. Yokoi, Fiber Bragg grating accelerometer for buildings and civil 
infrastructures, in: Proc. SPIE, 2001: pp. 479-486.

[59] 3D Systems Corporation, DuraForm ${ }^{\circledR}$ PA Plastic, (2010). http://www.3dsystems.com/sites/www.3dsystems.com/files/DS_DuraForm_PA_ US.pdf.

[60] P. Antunes, H. Lima, J. Monteiro, P.S. Andre, Elastic constant measurement for standard and photosensitive single mode optical fibres, Microw. Opt. Technol. Lett. 50 (2008) 2467-2469. doi:10.1002/mop.23660.

[61] R. Fernández, N. Gutierrez, PR-00206-TNO006_ED02 FADA-CATEC Project Report, Seville, 2013. 